\title{
Toxicity of Melastoma dodecandrum Lour. and its effects on lipopolysaccharide-induced inflammation and oxidative stress
}

\author{
GANG HUANG ${ }^{1}$, YULI GE ${ }^{2}$, ZHIHONG GUI ${ }^{3}$, MEIXIAO ZHU ${ }^{4}$, JIN LIU $^{5}$ and HUAFU WANG ${ }^{6}$ \\ Departments of ${ }^{1}$ Traditional Chinese Medicine, ${ }^{2}$ Infection, ${ }^{3}$ Nephrology, ${ }^{4}$ Pharmacy, ${ }^{5}$ Scientific Research Office \\ and ${ }^{6}$ Clinical Pharmacology, Lishui People's Hospital, Lishui, Zhejiang 323000, P.R. China
}

Received June 19, 2020; Accepted March 12, 2021

DOI: $10.3892 / \mathrm{etm} .2021 .10239$

\begin{abstract}
Melastoma dodecandrum Lour. (MDL) is component used in traditional Chinese medicine that is widely distributed throughout southern China. MDL has been long utilized in clinical treatment for various conditions, such as inflammation. However, the toxicity and underlying anti-inflammatory mechanism of MDL remain to be elucidated. In the present study, Sprague-Dawley rats received intragastric administration of MDL for 2 months, and the toxicity of MDL was investigated. The rats were treated with lipopolysaccharide (LPS) for $8 \mathrm{~h}$ to determine the potential anti-inflammatory mechanism of MDL. The results demonstrated that MDL alone did not affect the expression levels of factors associated with inflammation (IL-1 $\beta$, IL- 6 and TNF- $\alpha$ ) and oxidative stress [malondialdehyde (MDA), superoxide dismutase (SOD) and nitric oxide (NO)] in the rat serum and exerted no effects on rat liver and kidneys. By contrast, MDL attenuated LPS-induced inflammation and oxidative stress by regulating specific cytokines, such as IL-1 $\beta$, IL-6, TNF- $\alpha$, MDA, SOD and NO in the rat serum and alleviated LPS-induced liver and kidney damage. Additionally, compared with the LPS group, MDL inhibited $\mathrm{CD}^{+} \mathrm{T}$ cell differentiation into Th1 and Th17 cells and enhanced CD4 ${ }^{+}$ $\mathrm{T}$ cell differentiation into Th2 and Treg cells. MDL also suppressed reactive oxygen species (ROS) production and mitochondrial apoptosis by modulating mitochondrial apoptosis-related proteins in spleen $\mathrm{CD} 4^{+} \mathrm{T}$ cells. In conclusion, the results of the present study demonstrated the non-toxic nature of MDL and revealed that it alleviated LPS-induced
\end{abstract}

Correspondence to: Dr Huafu Wang, Department of Clinical Pharmacology, Lishui People's Hospital, 15 Dazhong Street, Lishui, Zhejiang 323000, P.R. China

E-mail: whf850405@126.com

Ms. Zhihong Gui, Department of Nephrology, Lishui People's Hospital, 15 Dazhong Street, Lishui, Zhejiang 323000, P.R. China E-mail: 153983313@qq.com

Key words: Melastoma dodecandrum Lour., inflammation, oxidative stress, $\mathrm{CD} 4^{+} \mathrm{T}$ cell, mitochondrial apoptosis inflammation and oxidative stress by regulating differentiation and ROS production in $\mathrm{CD} 4^{+} \mathrm{T}$ cells.

\section{Introduction}

She medicine has been reported as an effective therapeutic approach for alcoholic liver disease (1) and is involved in the regulation of oxidative stress and immunity (2). However, reports on the specific effects of She medicine, especially the mechanism underlying its effects on immunity, remain scarce.

The plant Melastoma dodecandrum Lour. (MDL) is an ingredient used in She medicine that belongs to the Melastomacea family and is mainly distributed throughout the regions south of China, such as Guizhou, Zhejiang and Yunnan (3). MDL is widely used in clinical settings to treat various diseases, including fever, sore throat, jaundice, hemorrhoids and herpes zoster (4). MDL contains numerous chemical components such as polysaccharides, flavonoids, amino acids and phenols, with functions such as promotion of blood circulation to arrest bleeding (5-7). The polysaccharides and flavonoids in MDL promote oxygen free radical scavenging and inhibit lipid peroxidation in the human erythrocyte membrane and liver mitochondria $(8,9)$. A previous study has reported that MDL suppresses oxidative stress by inhibiting nitric oxide production (10). Additionally, MDL can be used to treat a variety of inflammation-related diseases, including nephritis, enteritis and pelvic inflammation (11). However, the underlying anti-inflammatory mechanism of MDL has not been elucidated.

Quercetin (Que), the main component of MDL, is one of the most widely distributed and extensively studied flavonoids that exhibits robust anti-inflammatory and antioxidant properties (12). Que alleviates the symptoms of lupus nephritis by inhibiting the activation of $\mathrm{CD} 4^{+} \mathrm{T}$ cells (13) and suppresses PM2.5 (particulate matter $\leq 2.5 \mu \mathrm{m}$ )-induced oxidative stress and inflammatory response by decreasing $\mathrm{CD}^{+}$and $\mathrm{CD} 8^{+}$ $\mathrm{T}$ cell counts (14). Whether MDL suppresses oxidative stress and inflammation by regulating $\mathrm{CD} 4^{+} \mathrm{T}$ cells remains unclear. Additionally, the toxic effects of traditional Chinese medicine compounds, such as kidney injury, have attracted increasing attention (15) in order to promote the clinical use of MDL, the toxicity of MDL needs to be assessed. The present study aimed to evaluate the toxicity of MDL by subjecting normal experimental rats to intragastric administration of MDL and assessing pathological changes, inflammatory responses and 
oxidative stress. In addition. the effects of MDL and Que on inflammation, spleen $\mathrm{CD} 4^{+} \mathrm{T}$-cell differentiation and oxidative stress were investigated in rats suffering from lipopolysaccharide (LPS)-induced inflammation with the aim of elucidating the possible role of MDL in immune regulation.

\section{Materials and methods}

Preparation of the MDL solution. A Melastoma dodecandrum Lour. (identified by Professor Xueqian Wu, Zhejiang A \& F University, Hangzhou, China) decoction was prepared using $1 \mathrm{~kg}$ of raw medicinal material by boiling it in water for $30 \mathrm{~min}$ three times (ratio, 1:10, 1:8 and 1:6, respectively). The collected decoctions were filtered, centrifuged for $15 \mathrm{~min}$ at $3,000 \mathrm{x} \mathrm{g}$, $25^{\circ} \mathrm{C}$, concentrated at atmospheric pressure to $1 \mathrm{~g} / \mathrm{ml}$ and stored in a refrigerator at $4^{\circ} \mathrm{C}$ until subsequent experiments.

Determination of Que content in the MDL solution. A 100- $\mu 1$ aliquot of concentrated MDL solution was extracted with $300 \mu 1$ methanol ( $\geq 98 \%$, containing $5 \mu \mathrm{g} / \mathrm{ml}$ 2-chloro-l-phenylalanine as an internal standard) through vortex mixing for $30 \mathrm{sec}$. Following centrifugation at $15,348 \times \mathrm{g}$ at $4^{\circ} \mathrm{C}$ for $10 \mathrm{~min}$, a $5-\mu 1$ aliquot of the supernatant was analyzed by ultrahigh-performance liquid chromatography (UHPLC; 1290 Infinity II; Agilent Technologies, Inc.) using a UPLC BEH C18 Column (1.7 $\mu \mathrm{m}, 2.1 \times 100 \mathrm{~mm}$, Waters Corporation). The column temperature was maintained at $30^{\circ} \mathrm{C}$. The mobile phase consisted of water-acetonitrile (gradient elution) at a flow rate of $400 \mu \mathrm{l} / \mathrm{min}$, and the detector wavelength was set to $254 \mathrm{~nm}$. The compound concentrations were determined by evaluating the peak area and retention time.

Animals and experimental protocol. A total of 42 Sprague-Dawley rats (age, 7 weeks; weight, 200-220 g; 21 male and 21 female) were purchased from the Hubei Provincial Center for Disease Control and Prevention. The rats were maintained in a standard 12-h light/dark cycle with access to water and food ad libitum at $22-25^{\circ} \mathrm{C}$ and $50-60 \%$ humidity. To assess the toxicity of MDL, six rats received intragastric administration of MDL at a dose of $8.415 \mathrm{~g} / \mathrm{kg}$ (5X clinical dose) once a day for two months (MDL group). Untreated rats (CON group) received intragastric administration of an equal volume of saline once/day for two months. The rats were deeply anesthetized by intraperitoneal injection of pentobarbital sodium $(80 \mathrm{mg} / \mathrm{kg})$ and sacrificed by cervical dislocation, and the liver and kidneys were removed for pathological analysis. Blood obtained from the abdominal aorta was centrifuged at $800 \mathrm{x}$ g at $4^{\circ} \mathrm{C}$ for $10 \mathrm{~min}$. Serum was collected and stored at $-20^{\circ} \mathrm{C}$. The remaining rats were divided into five groups ( $\mathrm{n}=6$ per group) as follows: LPS, LPS + Que, LPS + Low, LPS + High and LPS + dexamethasone (Dex) as a positive control. The rats received intragastric administration of saline, Que $(10 \mathrm{mg} / \mathrm{kg}$; Chengdu Desite Biotechnology Co., Ltd.), low-dose MDL (1.683 g/ml, equivalent to clinical dose), high-dose MDL $(8.415 \mathrm{~g} / \mathrm{kg})$ and saline, respectively, once a day for two months. The rats in the LPS + Dex group were intraperitoneally injected with $40 \mu \mathrm{g} / \mathrm{ml}$ Dex only once following 2 month treatment (Sigma-Aldrich; Merck KGaA). After $30 \mathrm{~min}$, all rats were intraperitoneally injected with $5 \mathrm{mg} / \mathrm{kg}$ LPS (Beijing
Solarbio Science \& Technology Co., Ltd.) and maintained alive for $8 \mathrm{~h}$. Thereafter, the rats were deeply anesthetized by intraperitoneal injection of pentobarbital sodium $(80 \mathrm{mg} / \mathrm{kg})$ to obtain blood from the abdominal aorta. The rats were sacrificed by cervical dislocation, and the liver and kidneys were removed for pathological analysis. The serum, liver, and kidney samples were collected for subsequent experiments, and spleen $\mathrm{CD}^{+} \mathrm{T}$ cells were extracted. All animal procedures were performed at Wuhan Myhalic Biotechnology Co., Ltd. and approved by the Institutional Review Board of Wuhan Myhalic Biotechnology Co., Ltd. based on the ethical guidelines for animal care and use of the Model Animal Research Institute (approval no. HLK-20181009-01).

Biochemical analysis. Serum levels of C-reactive protein (CRP; cat. no. RA20041), interleukin (IL)-2 (cat. no. RA20132), IL- 6 cat. no. (RA20607), tumor necrosis factor (TNF)- $\alpha$ (cat. no. RA20035), IL-1 $\beta$ (cat. no. RA20020) and interferon (IFN)- $\gamma$ (cat. no. RA20684) were quantified using commercial enzyme-linked immunosorbent assay kits (Bioswamp Life Science Lab; Wuhan Beinlai Biotechnology Co., Ltd.) according to the manufacturer's instructions. Serum malondialdehyde (MDA), superoxide dismutase (SOD) and nitric oxide (NO) levels were quantified using corresponding commercial kits (Nanjing Jiancheng Bioengineering Institute) according to the manufacturer's instructions. Serum alanine aminotransferase (ALT), aspartate aminotransferase (AST), blood urea nitrogen (BUN) and creatinine (CRE) levels were evaluated using an automatic biochemical analyzer (Toshiba Corporation).

Hematoxylin and eosin staining. The liver and kidney tissue samples were fixed with $4 \%$ polyformaldehyde at $4^{\circ} \mathrm{C}$ for $4 \mathrm{~h}$, embedded in paraffin, cut into $4-5-\mu \mathrm{m}$ sections and mounted onto microscope slides. The sections were stained with hematoxylin and eosin (both Bioswamp) for 3 min each. Following dehydration using a concentration gradient of 80,98 and $100 \%$ ethyl alcohol and xylene and mounting with neutral balsam, the sections were visualized under a light microscope (magnification, x200; Leica Microsystems GmbH).

Isolation of $\mathrm{CD}^{+} \mathrm{T}$ cells. Spleen samples were obtained from the rats and maintained in pre-cooled RPMI-1640 medium (HyClone; Cytiva). The tissues were ground until no individual pieces were visible and filtered using a 200-target cell screen. The filtered cell suspension was centrifuged at $300 \mathrm{x} \mathrm{g}, 4^{\circ} \mathrm{C}$ for $5 \mathrm{~min}$, and red blood cells were lysed in red blood cell lysis buffer (cat. no. NH4CL2009, Tianjin Haoyang Biological Products Technology Co., Ltd.) for 2 min. Following centrifugation at $300 \mathrm{x} \mathrm{g}, 4^{\circ} \mathrm{C}$ for $5 \mathrm{~min}$, the cells were washed twice and resuspended in phosphate-buffered saline (Bioswamp) at a density of $1 \times 10^{7}$ cells $/ \mathrm{ml}$. Subsequently, the cells were stained with a CD4-fluorescein isothiocyanate (FITC) antibody (cat. no. MR5101; eBioscience) and subjected to cell sorting by flow cytometry (Moflo XDP; Beckman Coulter, Inc.).

Flow cytometry. Flow cytometry was performed to identify spleen $\mathrm{CD}^{+}{ }^{+} \mathrm{T}$ cells and evaluate mitochondrial membrane potential, ROS production and $\mathrm{CD} 4^{+} \mathrm{T}$ cell differentiation. To assess $\mathrm{CD} 4^{+} \mathrm{T}$ cell differentiation, the collected $\mathrm{CD} 4^{+} \mathrm{T}$ cells were incubated with $2 \mu \mathrm{l} \mathrm{CD4-FITC} \mathrm{antibody} \mathrm{in} \mathrm{the} \mathrm{dark} \mathrm{for}$ 
$30 \mathrm{~min}$ at $4^{\circ} \mathrm{C}$ and incubated with antibodies against IFN- $\gamma$ (cat. no. 507806; Biolegend, Inc.), IL-4 (cat. no. 12-7041-81; eBioscience) and IL-17 (cat. no. 12-7177-81; eBioscience) in the dark for $45 \mathrm{~min}$ at $4^{\circ} \mathrm{C}$ for the detection of $\mathrm{T}$ helper (Th) 1 , Th2 and Th17 cells, respectively. Similarly, the collected CD $4^{+}$ T cells were incubated with $2 \mu \mathrm{l} \mathrm{CD} 4-F I T C$ and CD25-PerCP (cat. no. 46-0390-82, eBioscience) in the dark for $30 \mathrm{~min}$ at $4^{\circ} \mathrm{C}$ followed by $2 \mu \mathrm{l}$ Foxp3-PE antibody (cat. no. 12-4777-41; eBioscience) in the dark for $45 \mathrm{~min}$ at $4^{\circ} \mathrm{C}$ for the detection of $\mathrm{T}$ regulatory (Treg) cells. Mitochondrial membrane potential was evaluated using a Mitochondrial Membrane Potential Detection kit (Bioswamp) according to the manufacturer's instructions. Briefly, CD $4^{+} \mathrm{T}$ cells $\left(5 \times 10^{5}\right)$ were stained with 5,5',6,6'-tetrachloro-1,1',3,3' tetraethylbenzimidazolylcarbocyanine iodide (JC-1) for $20 \mathrm{~min}$ at $37^{\circ} \mathrm{C}$. Following centrifugation at $600 \mathrm{x} \mathrm{g}$ for $4 \mathrm{~min}$ at $4^{\circ} \mathrm{C}$ twice, the cells were resuspended in JC-1 staining buffer and subjected to flow cytometry. To detect ROS production, the cells were suspended at a density of $1 \times 10^{7}$ cells $/ \mathrm{ml}$ and incubated with diluted $2^{\prime}, 7^{\prime}$-dichlorofluorescin diacetate (DCFH-DA) fluoroprobes $(10 \mu \mathrm{mol} / \mathrm{l}$; Invitrogen; Thermo Fisher Scientific, Inc.) for $20 \mathrm{~min}$ at $37^{\circ} \mathrm{C}$ with gentle shaking every $4 \mathrm{~min}$. Non-attached DCFH-DA was removed, and the cells were subjected to flow cytometry (NovoCyte, ACEA Bioscience, Inc.) and the data was analyzed using NovoExpress software version 1.3.0.

Western blotting. Total proteins were extracted from $\mathrm{CD}^{+}$ $\mathrm{T}$ cells using radioimmunoprecipitation assay lysis buffer (Bioswamp), followed by quantification using a bicinchoninic acid kit (Bioswamp) according to the manufacturer's instructions. Proteins (20 $\mu \mathrm{g}$ from each sample) were separated by sodium dodecyl sulfate-polyacrylamide gel electrophoresis on a $12 \%$ gel and transferred onto polyvinylidene fluoride membranes (EMD Millipore). Following blocking using $5 \%$ skimmed milk at $25^{\circ} \mathrm{C}$ for $2 \mathrm{~h}$, the membranes were incubated with primary antibodies against Bad (cat. no. PAB32756), B-cell lymphoma-2 (Bcl-2, cat. no. PAB30041), p53 (cat. no. PAB30082), GAPDH (cat. no. PAB36269; all 1:1,000; all Bioswamp), cleaved caspase-9 (cat. no. ab2324) and cytochrome $c$ (Cyt-C; cat. no. ab90529; both 1:1,000; both Abcam) overnight at $4^{\circ} \mathrm{C}$, followed by incubation with horseradish peroxidase-labeled goat anti-rabbit IgG secondary antibody (1:20,000; cat. no. PAB160011; Bioswamp) for $1 \mathrm{~h}$ at room temperature. Protein bands were visualized using a Tanon-5200 apparatus and the gray values were analyzed using the TANON GIS software (both Tanon Science and Technology Co., Ltd.). GAPDH was used as an internal reference.

Statistical analysis. Data are presented as the mean \pm standard deviation (SD). Differences between more than two groups were analyzed using one-way analysis of variance followed by the Tukey's test using SPSS 19.0 software (IBM Corp.). $\mathrm{P}<0.05$ was considered to indicate a statistically significant difference.

\section{Results}

Assessment of MDL toxicity. The chemical composition of MDL was detected using UHPLC. The UHPLC-quadrupole time-of-flight mass spectrometry (QTOF-MS) fingerprints of MDL in the negative and positive modes are presented in Figs. S1 and S2, respectively, and the UHPLC-QTOF-MS detection of the chemical composition of MDL is presented in Tables SI and SII. The results demonstrated that Que was an important chemical component of MDL (Fig. S1 and Table SI). After rats were treated with MDL $(8.415 \mathrm{~g} / \mathrm{kg})$, the toxicity of MDL was assessed. As demonstrated in Fig. 1A, the liver sections from the control and MDL-treated rats exhibited normal lobular architecture without inflammation and necrosis, and the kidney tissues exhibited clear texture without inflammatory response or edema. Additionally, MDL did not affect the levels of factors associated with liver damage (ALT and AST) and kidney (BUN and CRE), inflammation (IL-1 $\beta$, IL-6 and TNF- $\alpha$ ) or oxidative stress (MDA, SOD and NO) (Fig. 1B-D). Collectively, these results demonstrated that MDL was non-toxic to rats.

MDL alleviates LPS-induced liver and kidney injuries in rats. Liver and kidney injuries were assessed in rats following LPS treatment. In the LPS group, the liver cells were disorganized with inflammatory infiltration and necrosis. However, the liver sections of rats treated with Que, high-dose MDL and Dex exhibited normal lobular architecture without evident inflammation. In terms of the kidney structure, the LPS group presented with exfoliation of renal tubular epithelial cells and glomerular inflammatory response, which were ameliorated by Que, high-dose MDL and Dex (Fig. 2A). Compared with those in the LPS group, the expression levels of ALT, AST, BUN and CRE were decreased by low-dose MDL $(\mathrm{P}<0.05)$ and further inhibited by high-dose MDL ( $\mathrm{P}<0.05)$ (Fig. 2B). These results indicated that MDL alleviated LPS-induced liver and kidney injuries.

MDL inhibits LPS-induced inflammation in rats. The levels of inflammation-related factors were detected in the serum of LPS-treated rats (Fig. 3). Compared with those in the LPS group, the levels of IL-1 $\beta$, IL-2, IL-6, CRP, IFN- $\gamma$ and TNF- $\alpha$ were inhibited by low-dose MDL $(\mathrm{P}<0.05)$ and further inhibited by high-dose MDL $(\mathrm{P}<0.05)$. The effects of high-dose MDL and Que on the expression of these factors were similar, but not as prominent as those of Dex $(\mathrm{P}<0.05)$. These results indicated that MDL attenuated LPS-induced inflammation in rats by regulating the levels of inflammation-related factors, and MDL exerted a superior effect at high doses compared with that exerted at low doses.

MDL affects spleen $C D 4^{+} T$-cell differentiation in LPStreated rats. Following LPS treatment, spleen $\mathrm{CD}_{4}^{+}$ $\mathrm{T}$ cells were obtained from rats, and their differentiation was analyzed. Spleen $\mathrm{CD}^{+} \mathrm{T}$ cells were successfully obtained, as demonstrated by the high positive expression of CD4 (>98\%) (Fig. 4). Compared with the LPS group, MDL inhibited $\mathrm{CD}^{+}{ }^{+}$T-cell differentiation into Th1 and Th17 cells and enhanced $\mathrm{CD} 4^{+} \mathrm{T}$-cell differentiation into Th2 and Treg cells (Fig. 5).

MDL attenuates LPS-induced oxidative stress and mitochondrial apoptosis in $\mathrm{CD}^{+} \mathrm{T}$ cells. Compared with those in the LPS group, ROS production and the 


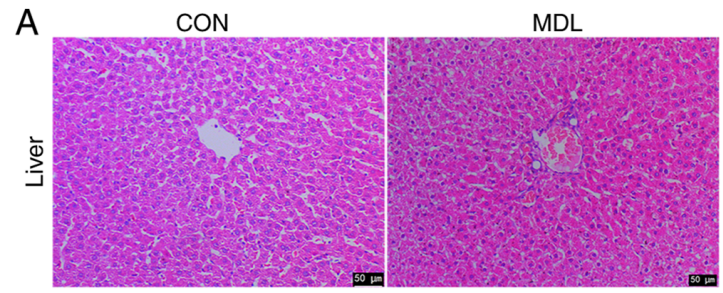

B

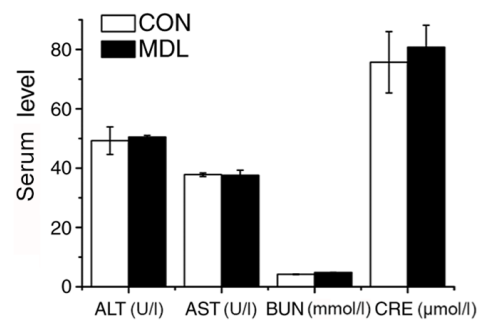

C

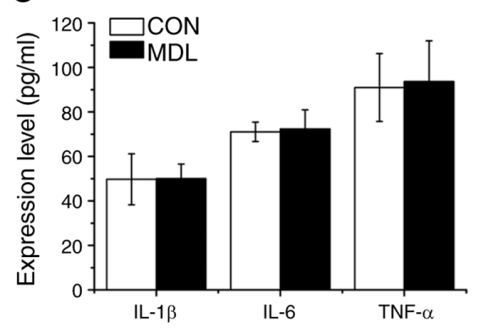

CON

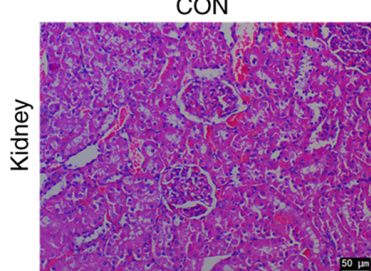

$\mathrm{D}$

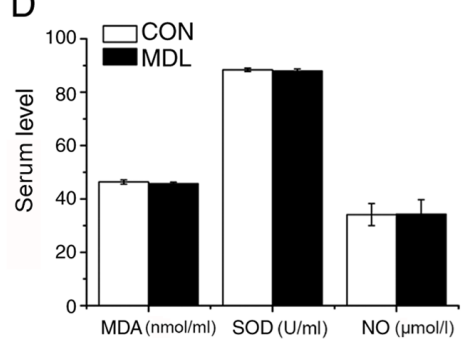

Figure 1. Detection of MDL toxicity. (A) H\&E staining of the rat liver and kidney tissues. (B) Levels of ALT, AST, BUN and CRE in rat serum. (C) Levels of IL-1 $\beta$, IL- 6 and TNF- $\alpha$ in rat serum. (D) Levels of MDA, SOD and NO in rat serum. Data are presented as the mean \pm SD. Scale bar, $50 \mu \mathrm{m}$. $\mathrm{n}=3$. MDL, Melastoma dodecandrum Lour. solution; CON, control; ALT, alanine aminotransferase; AST, aspartate aminotransferase; BUN, blood urea nitrogen; CRE, creatinine; MDA, malondialdehyde; SOD, superoxide dismutase; NO, nitric oxide.
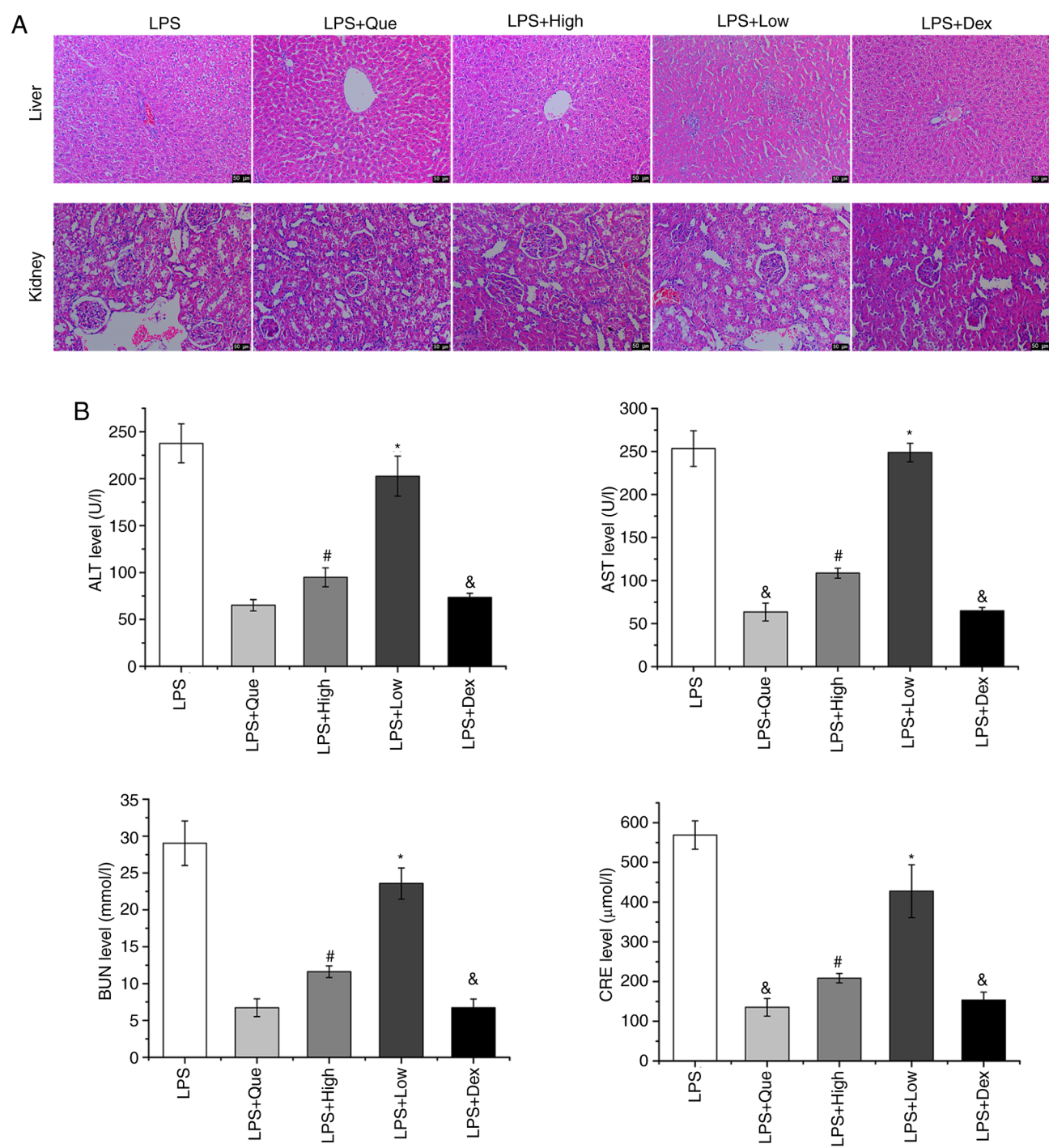

Figure 2. Melastoma dodecandrum Lour. solution alleviates LPS-induced liver and kidney injuries in rats (A) H\&E staining of the rat liver and kidney tissue. (B) Levels of ALT, AST, BUN, and CRE in rat serum. Data are presented as the mean $\pm \mathrm{SD}$. " $\mathrm{P}<0.05 \mathrm{vs}$. LPS; ${ }^{\mathrm{P}} \mathrm{P}<0.05 \mathrm{vs}$. LPS + Low; ${ }^{\&} \mathrm{P}<0.05 \mathrm{vs}$. LPS + High. Scale bar, $50 \mu \mathrm{m}$. $\mathrm{n}=6$. LPS, lipopolysaccharide; Que, quercetin; Dex, dexamethasone; high, $8.415 \mathrm{mg} / \mathrm{kg}$ Melastoma dodecandrum Lour. solution; low, $1.683 \mathrm{mg} / \mathrm{kg}$ Melastoma dodecandrum Lour. solution; ALT, alanine aminotransferase; AST, aspartate aminotransferase; BUN, blood urea nitrogen; CRE, creatinine. 

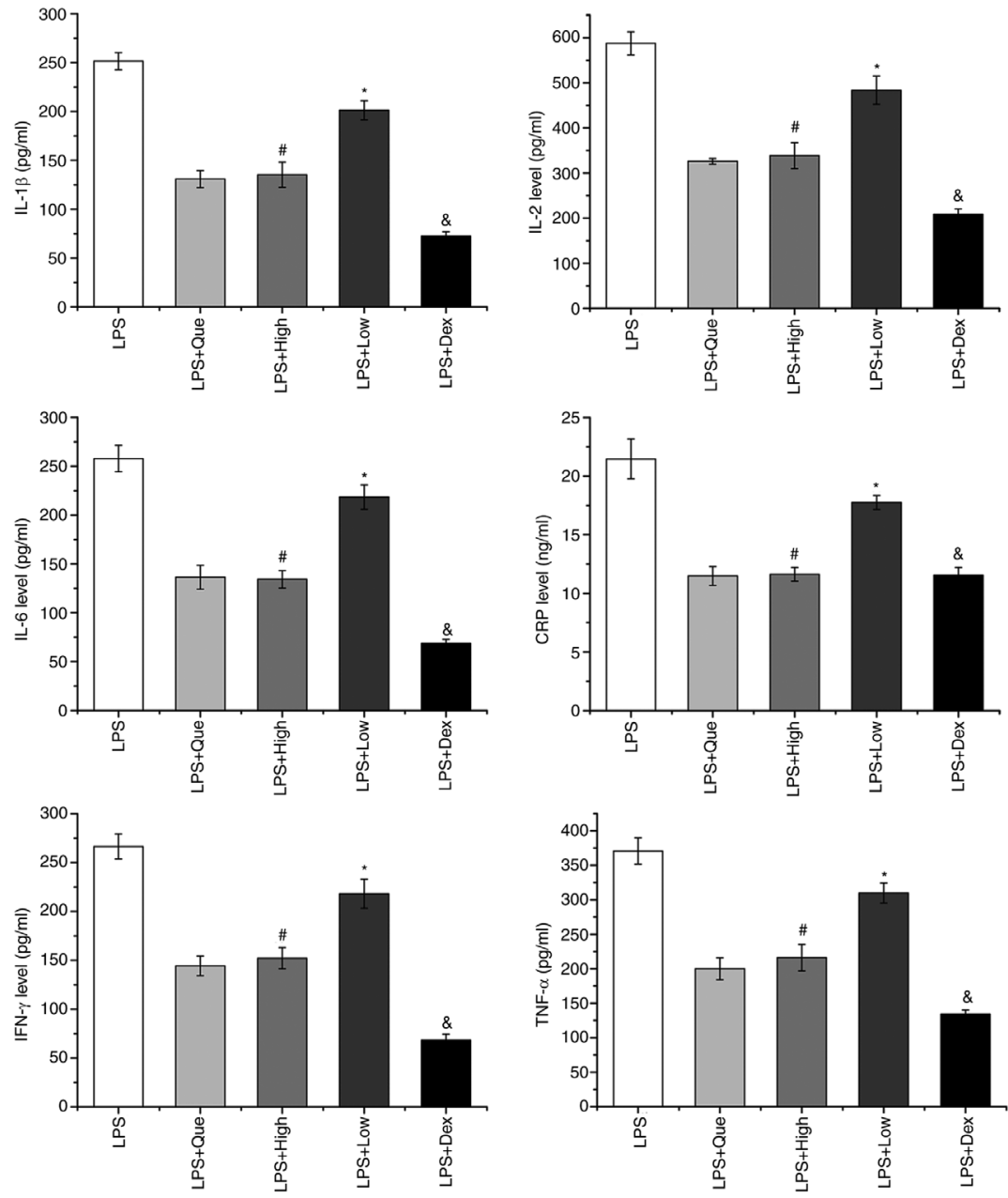

Figure 3. Melastoma dodecandrum Lour. solution inhibits LPS-induced inflammation in rats. The levels of inflammation-related factors IL-1 $\beta$, IL-2, IL-6, CRP, IFN $-\gamma$, and TNF- $\alpha$ were detected in the rat serum. Data are presented as the mean \pm SD. ${ }^{*} \mathrm{P}<0.05$ vs. LPS; ${ }^{\text {}} \mathrm{P}<0.05$ vs. LPS + Low; ${ }^{\text {\& }} \mathrm{P}<0.05$ vs. LPS + High. n=6. LPS, lipopolysaccharide; Que, quercetin; Dex, dexamethasone; high, $8.415 \mathrm{mg} / \mathrm{kg}$ Melastoma dodecandrum Lour. solution; low, $1.683 \mathrm{mg} / \mathrm{kg}$ Melastoma dodecandrum Lour. solution; CRP, C-reactive protein.
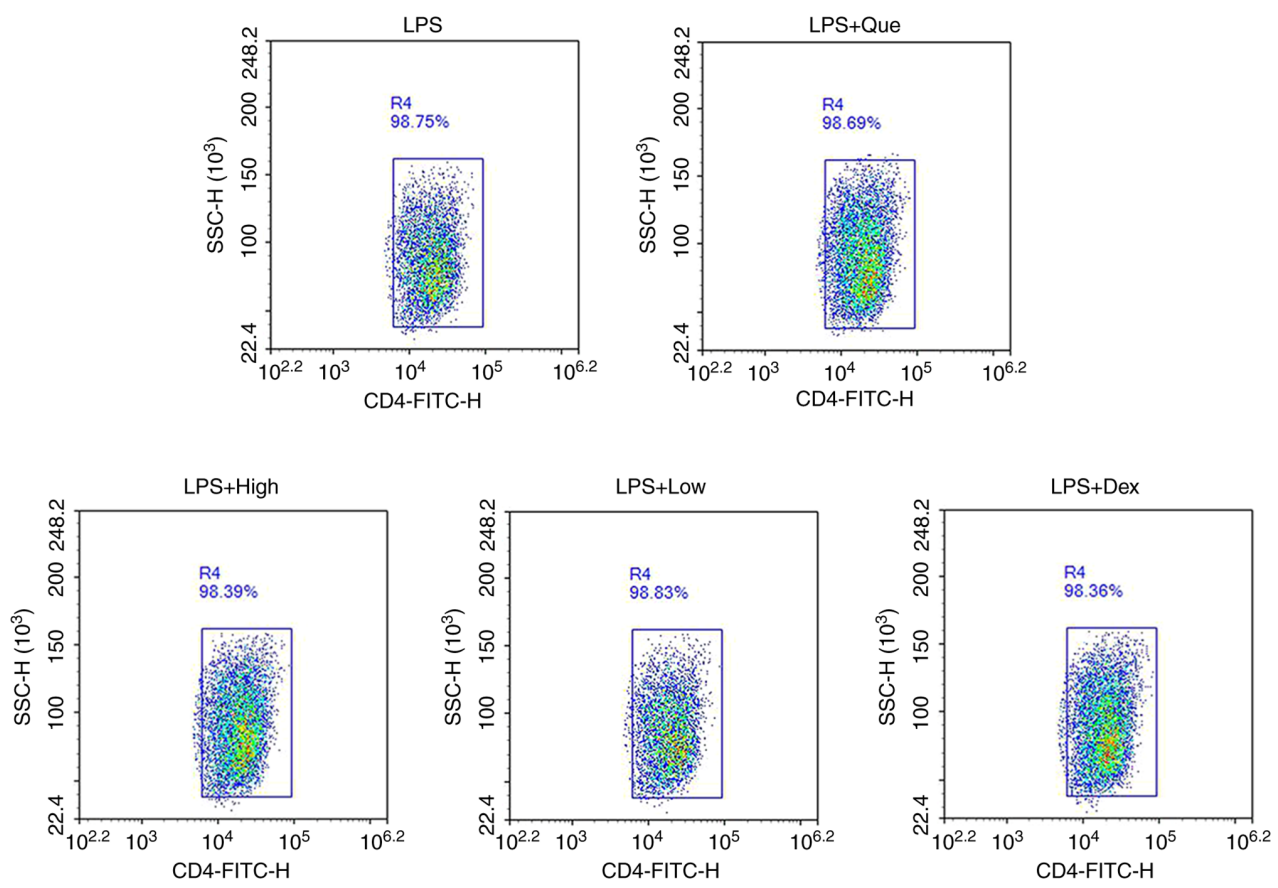

Figure 4. Positive expression of $\mathrm{CD}^{+}{ }^{+} \mathrm{T}$ cells in rat spleen samples. LPS, lipopolysaccharide; Que, quercetin; Dex, dexamethasone; high, $8.415 \mathrm{mg} / \mathrm{kg}$ Melastoma dodecandrum Lour. solution; low, $1.683 \mathrm{mg} / \mathrm{kg}$ Melastoma dodecandrum Lour. solution; SSC-H, side scatter height. 

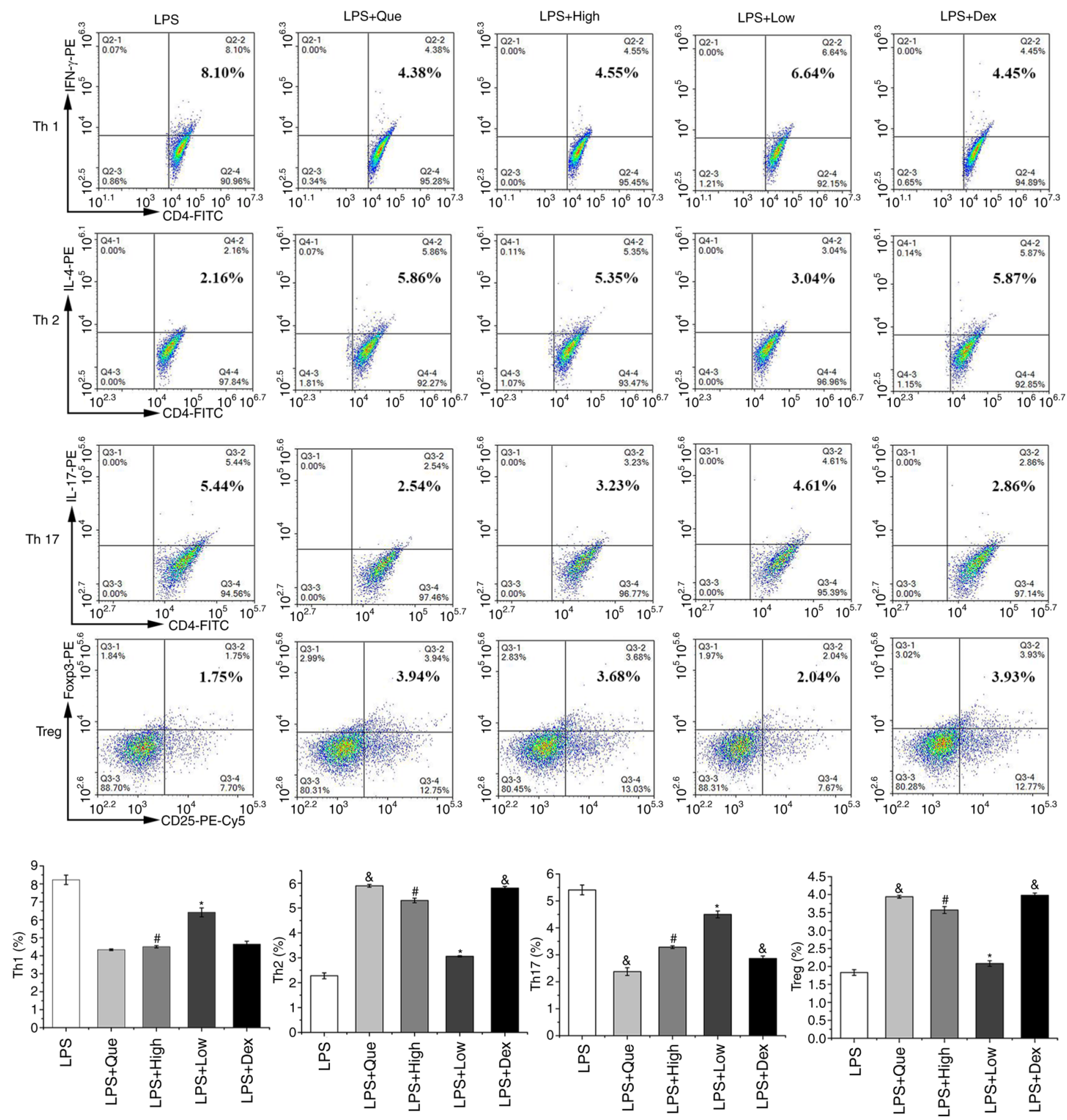

Figure 5. Melastoma dodecandrum Lour. solution affects the differentiation of spleen $\mathrm{CD} 4^{+} \mathrm{T}$ cells in LPS-treated rats. The percentages of $\mathrm{CD} 4^{+} \mathrm{T}$ cells that differentiated into Th1, Th2, Th17 and Treg cells were examined by flow cytometry. Data are presented as the mean \pm SD. ${ }^{P}<<0.05$ vs. LPS; ${ }^{*} \mathrm{P}<0.05$ vs. LPS + Low; ${ }^{\circledR}$ P $<0.05$ vs. LPS + High. n=3. LPS, lipopolysaccharide; Que, quercetin; Dex, dexamethasone; high, $8.415 \mathrm{mg} / \mathrm{kg}$ Melastoma dodecandrum Lour. solution; low, $1.683 \mathrm{mg} / \mathrm{kg}$ Melastoma dodecandrum Lour. solution; Th, T helper; Treg, T regulatory.

proportion of cells exhibiting a decrease in the mitochondrial membrane potential were suppressed by low-dose MDL and further suppressed by Que, high-dose MDL and Dex (Figs. 6A and 7A). In addition, the levels of oxidative stress-related markers were analyzed. Compared with those in the LPS group, high- and low-dose MDL inhibited the levels of MDA and NO and promoted the level of SOD. High-dose MDL exhibited a superior effect compared with low-dose MDL (Fig. 6B). Additionally, the expression levels of mitochondrial apoptosis-related proteins were detected; compared with those in the LPS group, high- and low-dose MDL promoted the expression levels of the antiapoptotic protein $\mathrm{Bcl}-2$ and inhibited the expression of the proapoptotic proteins Bad, cleaved caspase-9, Cyt-C and p53. High-dose MDL demonstrated a superior effect compared with low-dose MDL (Fig. 7B).

\section{Discussion}

The results of the present study validated the non-toxic nature of MDL, which was indicated by the lack of effects of MDL on oxidative stress and inflammation in normal rats following 2-month intragastric administration. Additionally, MDL alleviated LPS-induced inflammation, oxidative stress 
A
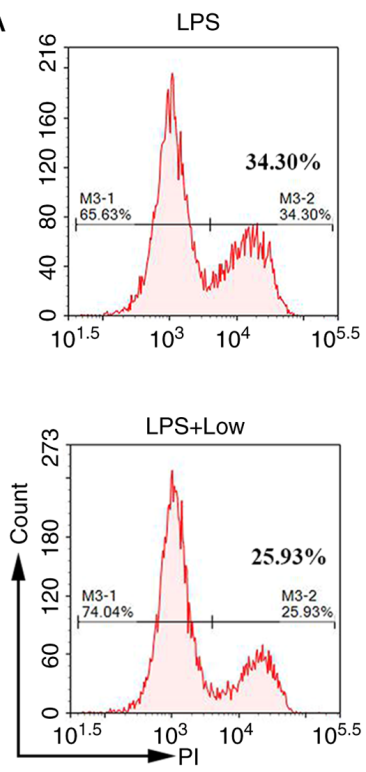
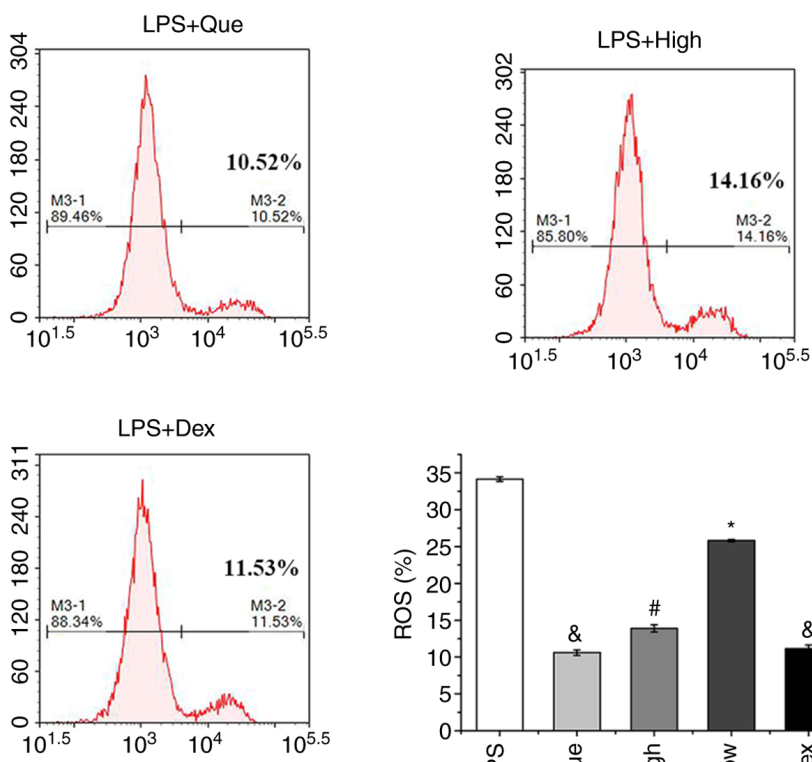

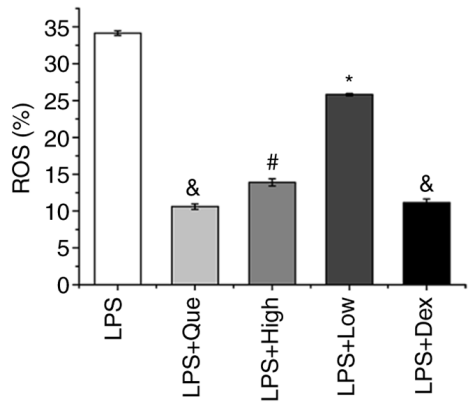

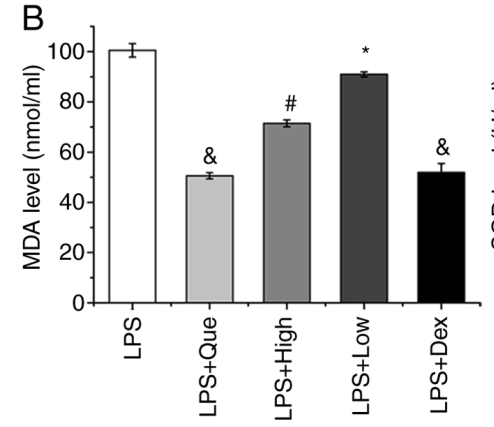
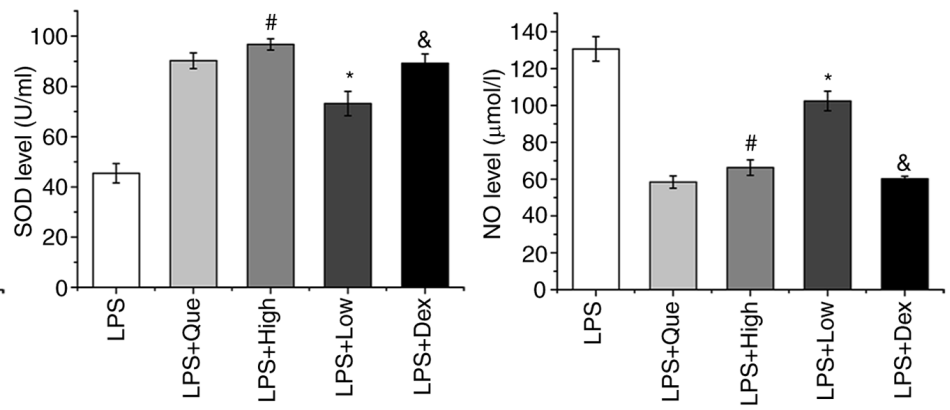

Figure 6. Melastoma dodecandrum Lour. solution alleviates LPS-induced oxidative stress in CD4 ${ }^{+} \mathrm{T}$ cells. (A) ROS production in CD4 $4^{+} \mathrm{T}$ cells. (B) Levels of $\mathrm{MDA}$, SOD and $\mathrm{NO}$ in $\mathrm{CD} 4{ }^{+} \mathrm{T}$ cells. Data are presented as the mean $\pm \mathrm{SD}$. ${ }^{*} \mathrm{P}<0.05$ vs. LPS; $\mathrm{P}<0.05$ vs. LPS + Low; ${ }^{\circ} \mathrm{P}<0.05$ vs. LPS + High. $\mathrm{n}=6$. LPS, lipopolysaccharide; Que, quercetin; Dex, dexamethasone; high, $8.415 \mathrm{mg} / \mathrm{kg}$ Melastoma dodecandrum Lour. solution; low, $1.683 \mathrm{mg} / \mathrm{kg}$ Melastoma dodecandrum Lour. solution; ROS, reactive oxygen species; MDA, malondialdehyde; SOD, superoxide dismutase; NO, nitric oxide.

and damage to the liver and kidneys induced by LPS in rats. Furthermore, MDL regulated the differentiation and mitochondrial apoptosis of spleen $\mathrm{CD}^{+} \mathrm{T}$ cells in LPS-treated rats.

$\mathrm{CD}^{+} \mathrm{T}$ cells are important mediators of immunological memory, the diminution of which can result in susceptibility to infection and serve indispensable roles in the modulation of adaptive immunity against a variety of pathogens (16). During T-cell receptor activation in specific cytokine microenvironments, naïve $\mathrm{CD}^{+} \mathrm{T}$ cells may differentiate into subsets such as Th (including Th1, Th2 and Th17) or Treg cells (16). These subsets secrete numerous inflammatory cytokines and play vital functions in host defense against foreign pathogens $(17,18)$. However, uncontrolled inflammatory response mediated by the subsets of $\mathrm{CD}^{+} \mathrm{T}$ cells may lead to inflammatory disorders and tissue damage (19). Th1 cells are involved in cellular immunity against intracellular microorganisms and are characterized by the generation of IFN- $\gamma$ and IL-2 (20,21). IFN- $\gamma$ is produced by Th1 cells and serves an important role in the maintenance of cytotoxic $\mathrm{T}$ cell differentiation. By contrast, Th2 cells are required for humoral immunity to combat extracellular pathogens and parasites and are characterized by the production of IL-4, IL-5 and IL-13 (20). Th17 cells mainly secrete cytokines of the IL-17 family (including IL-17A and IL-17F), IL-21 and IL-22, with high capacity for recruitment of neutrophils and macrophages, resulting in an inflammatory reaction (22). The differentiation of Th17 cells is associated with the stimulation of transforming growth factor- $\beta$ and IL-6 (23). Treg cells are involved in the prevention of autoimmune diseases and the maintenance of immune balance (24). Previous reports have demonstrated that promotion of the differentiation of $\mathrm{CD}^{+} \mathrm{T}$ cells into Treg cells inhibited LPS-induced inflammation (25). As an important component of MDL, Que is reportedly involved in the regulation of $\mathrm{CD}^{+} \mathrm{T}$-cell differentiation, thereby participating in immunoregulation. Que inhibits the differentiation of $\mathrm{CD}^{+} \mathrm{T}$ cells into Th17 cells in IL-17-induced osteoclastogenesis in rheumatoid arthritis and is considered to be a potential therapeutic option for the management of bone-destructive processes in rheumatoid arthritis (26). In the present study, similar to the results reported for Que, MDL inhibited the differentiation of $\mathrm{CD}^{+}$ $\mathrm{T}$ cells into Th1 and Th17 cells in LPS-treated rats, while promoting their differentiation into Th2 and Treg cells. 
A
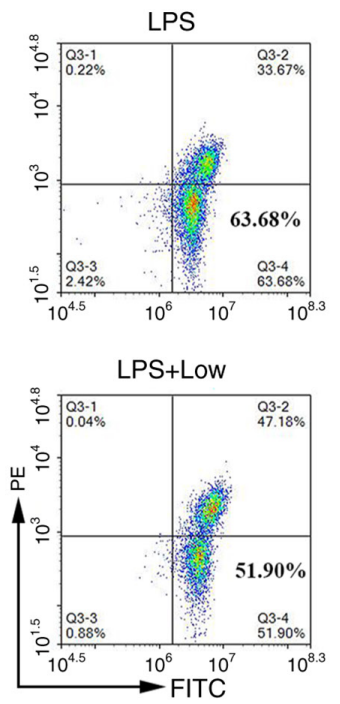

B

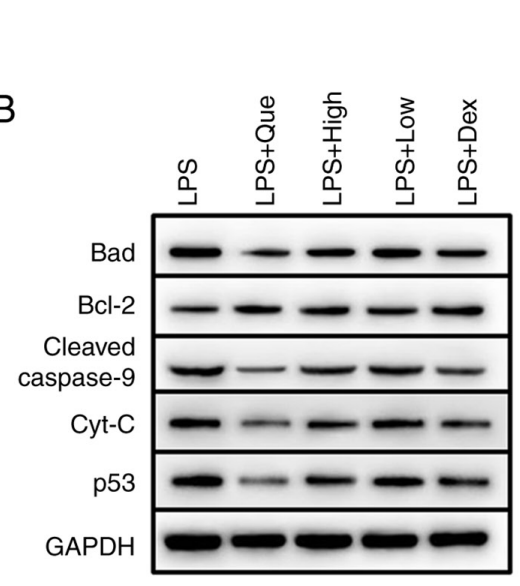

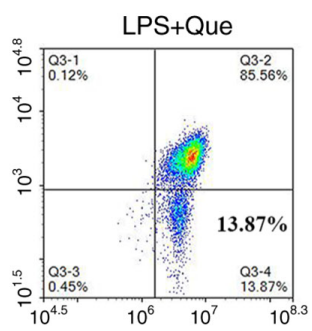

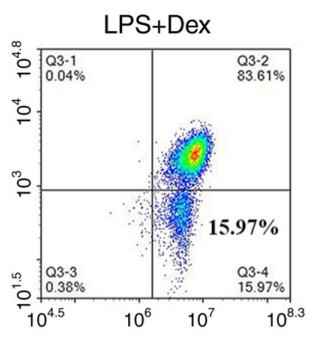

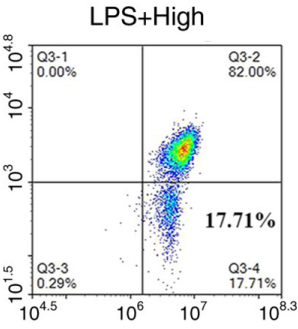

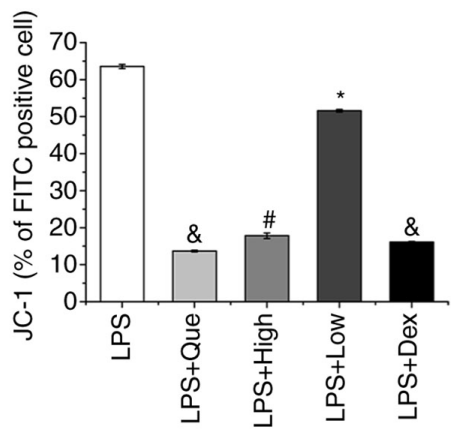

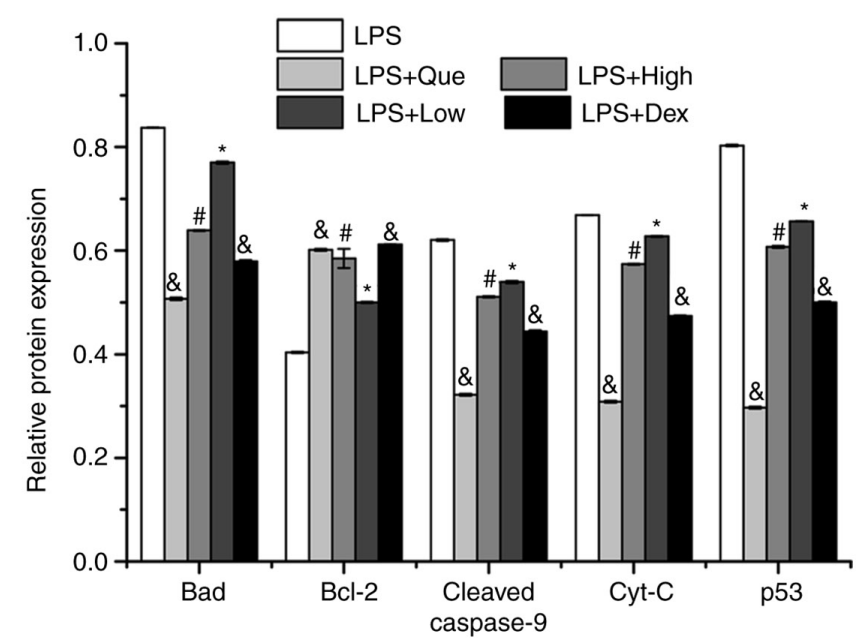

Figure 7. MDL alleviates LPS-induced mitochondrial apoptosis in $\mathrm{CD} 4^{+} \mathrm{T}$ cells. (A) Percentage of $\mathrm{CD} 4^{+} \mathrm{T}$ cells exhibiting a decrease in the mitochondrial membrane potential. (B) Relative expression of mitochondrial apoptosis-related proteins in CD4+ $\mathrm{T}$ cells. Data are presented as the mean $\pm \mathrm{SD}$. " $\mathrm{P}<0.05 \mathrm{vs.} \mathrm{LPS}$; ${ }^{\#} \mathrm{P}<0.05$ vs. LPS + Low; ${ }^{\circ} \mathrm{P}<0.05$ vs. LPS + High. $\mathrm{n}=3$. LPS, lipopolysaccharide; Que, quercetin; Dex, dexamethasone; high, $8.415 \mathrm{mg} / \mathrm{kg}$ Melastoma dodecandrum Lour. solution; low, $1.683 \mathrm{mg} / \mathrm{kg}$ Melastoma dodecandrum Lour. solution; Cyt-C, cytochrome $c$.

Exogenous pathogens result in metabolic disorders associated with $\mathrm{CD} 4^{+} \mathrm{T}$ cells and induce inflammation, promoting the production of ROS in T cells (27). ROS is mainly produced in the mitochondria, which are a major target of oxidative damage induced by ROS-containing lipids, proteins and DNA $(28,29)$. p53 is a tumor-suppressing gene that participates in the regulation of apoptosis. When ROS induces irreversible DNA damage, p53 is involved in the regulation of apoptosis through upregulation of Bax and downregulation of Bcl-2 (30). Both Bax and Bcl-2 belong to the Bcl-2 family and regulate apoptosis by modulating mitochondrial membrane permeability (31). Bax activation and $\mathrm{Bcl}-2$ inhibition promote mitochondrial permeability transition pore opening, resulting in the release of Cyt-C from the mitochondria into the cytoplasm, which in turn activates caspase-9 and its downstream effector caspase 3 to enhance apoptosis (30). Bad is another member of the Bcl-2 family that participates in the mediation of mitochondrial apoptosis (32). The present study demonstrated that MDL attenuated LPS-induced inflammation by regulating inflammation-associated cytokines, including IL-6 and IFN- $\gamma$. Additionally, MDL inhibited ROS production in $\mathrm{CD} 4^{+} \mathrm{T}$ cells, which suppressed mitochondrial apoptosis.

In conclusion, the results of the present study verified the non-toxic nature of MDL and demonstrated its immunomodulatory effects, which may be mediated by $\mathrm{CD} 4^{+}$ T-cell differentiation, alleviating LPS-induced inflammation. Additionally, MDL suppressed LPS-induced mitochondrial apoptosis of $\mathrm{CD} 4^{+} \mathrm{T}$ cells by impairing ROS production. These results provide a theoretical basis for the optimized clinical application of MDL. As the regulation of TCM is systematic, based on the complex composition of MDL, other potential regulatory functions of MDL will be investigated in follow-up studies.

\section{Acknowledgements}

The authors would like to thank Professor Xueqian Wu (Zhejiang A\&F University, Hangzhou, China) for identifying Melastoma dodecandrum Lour. 


\section{Funding}

This work was supported by the Lishui Science and Technology Planning Project (grant no. 2016zdyf02), the Zhejiang Pharmaceutical Association Hospital Pharmaceutical Research Project (grant no. 2016ZYY40) and The Lishui High-level Talent Fund Project (grant no. 2017RC19).

\section{Availability of data and materials}

The datasets used and/or analyzed during the current study are available from the corresponding author on reasonable request.

\section{Authors' contributions}

GH and HW designed the study. GH, YG, ZG, MZ and JL performed the experiments and analyzed data. GH drafted the manuscript. HW supervised this project and revised the manuscript. GH and HW confirm the authenticity of all the raw data. All authors read and approved the final manuscript.

\section{Ethics approval and consent to participate}

All animal procedures were approved by the Institutional Review Board of Wuhan Myhalic Biotechnology Co.,Ltd. based on the ethical guidelines for animal care and use of the Model Animal Research Institute (approval no. HLK-20181009-01).

\section{Patient consent for publication}

Not applicable.

\section{Competing interests}

The authors declare that they have no competing interests.

\section{References}

1. Zheng S and Lei H: The effects of She medicine on the serum index and imaging related to alcoholic liver disease. Chin Arch Tradit Chin Med 28: 342-343, 2010.

2. Cai M, Cao M, Wang J and Zhang X: Comparison of antioxidant capacity of 18 She medicine plants. Chin Tradit Pat Med 35: 2283-2286, 2013.

3. Wang J, Jia Z, Zhang Z, Wang Y, Liu X, Wang L and Lin R: Analysis of chemical constituents of Melastoma dodecandrum Lour. byUPLC-ESI-Q-exactive focus-MS/MS. Molecules 22: 476, 2017.

4. Wang J, Zhang N, Lan J, et al: Biological effects of Melastoma dodecandrum Lour on coagulation function in rats with limb ischemiareperfusion injury. Zhejiang J Integr Tradit Chin West Med 27: 562-564, 2017.

5. Zhai XL, Ni J and Gu YL: Separation of phenols from Melastoma dodecandrum with macroporous resins. Chin Tradit Herbal Drugs 39: 196-199, 2008.

6. Zhang C, Chen Z, Yao H,Lin Y and Fang Y: Isolation, purification and structural analysis of polysacharide MD1 from Melastoma dodecandrum Lour. Acad J Guangzhou Med Coll 30: 21-24, 2002.

7. Zhou T: Effect of Melastoma dodecandrum Lour injection on rabbit blood. J Guangzhou Coll Tradit ChinMed 12: 40, 1995.

8. Lapshina EA, Zamaraeva M, Cheshchevik VT, Olchowik-Grabarek E, Sekowski S, Zukowska I, Golovach NG, Burd VN and Zavodnik IB: Cranberry flavonoids prevent toxic rat liver mitochondrial damage in vivo and scavenge free radicals in vitro. Cell Biochem Funct 33:202-210, 2015.

9. Zhang C, Yao H, Xu L, Yang F and Fang Y: Effects of polysacharide MD1 on eliminating $\mathrm{O}^{-2}, \mathrm{OH}$ and anti-peroxidation upon human erythrocyte membrane. Acad J Guangzhou Med Coll 30: 18-24, 2002 (In Chinese).
10. Ishii R, Saito K, Horie M, Shibano T, Kitanaka S and Amano F: Inhibitory effects of hydrolyzable tannins from Melastoma dodecandrum Lour. on nitric oxide production by a murine macrophage-like cell line, RAW264.7, activated with lipopolysaccharide and interferon-gamma. Biol Pharm Bull 22: 647-653, 1999.

11. Zhang C: Studies on the chemical constituents and pharmacological activities of Melastoma dodecandrum Lour. Guangzhou Univ Technol, 2003

12. Eid HM and Haddad PS: The antidiabetic potential of quercetin: Underlying mechanisms. Curr Med Chem 24: 355-364, 2017.

13. Li W, Li H, Zhang M, Wang M, Zhong Y, Wu H, Yang Y, Morel L and Wei Q: Quercitrin ameliorates the development of systemic lupus erythematosus-like disease in a chronic graft-versus-host murine model. Am J Physiol Renal Physiol 311: F217-F226, 2016.

14. Liu W, Zhang M, Feng J, Fan A, Zhou Y and Xu Y: The influence of quercetin on maternal immunity, oxidative stress, and inflammation in mice with exposure of fine particulate matter during gestation. Int J Environ Res Public Health 14: 592, 2017.

15. Xu XL, Yang LJ and Jiang JG: Renal toxic ingredients and their toxicology from traditional Chinese medicine. Expert Opin Drug Metab Toxicol 12: 149-159, 2016.

16. Zhu J, Yamane H and Paul WE: Differentiation of effector CD4 T cell populations (*). Annu Rev Immunol 28: 445-489, 2010

17. Sałkowska A, Karaś K, Karwaciak I, Walczak-Drzewiecka A, Krawczyk M, Sobalska-Kwapis M, Dastych J and Ratajewski M: Identification of novel molecular markers of human Th17 cells. Cells 9: 1611, 2020.

18. Hirahara $\mathrm{K}$ and Nakayama T: $\mathrm{CD}^{+} \mathrm{T}$-cell subsets in inflammatory diseases: Beyond the Th1/Th2 paradigm. Int Immunol 28: 163-171, 2016.

19. Fang D and Zhu J: Molecular switches for regulating the differentiation of inflammatory and IL-10-producing anti-inflammatory T-helper cells. Cell Mol Life Sci 77: 289-303, 2020.

20. Zhou L, Chong MM and Littman DR: Plasticity of $\mathrm{CD}^{+} \mathrm{T}$ cell lineage differentiation. Immunity 30: 646-655, 2009.

21. Szabo SJ, Kim ST, Costa GL, Zhang X, Fathman CG and Glimcher LH: A novel transcription factor, T-bet, directs Th1 lineage commitment. Cell 100: 655-669, 2000.

22. Agita A and Alsagaff MT: Inflammation, immunity, and hypertension. Acta Med Indones 49: 158-165, 2017.

23. Chen Z, Laurence A and O'Shea JJ: Signal transduction pathways and transcriptional regulation in the control of Th17 differentiation. Semin Immunol 19: 400-408, 2007.

24. Dominguez-Villar M and Hafler DA: Regulatory T cells in autoimmune disease. Nat Immunol 19: 665-673, 2018.

25. Zheng Y, Dong C, Yang J, Jin Y, Zheng W, Zhou Q, Liang Y, Bao L, Feng G, Ji J, et al: Exosomal microRNA-155-5p from PDLSCs regulated Th17/Treg balance by targeting sirtuin-1 in chronic periodontitis. J Cell Physiol 234: 20662-20674, 2019.

26. Kim HR, Kim BM, Won JY, Lee KA, Ko HM, Kang YS, Lee SH and Kim KW: Quercetin, a plant polyphenol, has potential for the prevention of bone destruction in rheumatoid arthritis. J Med Food 22: 152-161, 2019.

27. Ma C, Kesarwala AH, Eggert T, Medina-Echeverz J, Kleiner DE, Jin P, Stroncek DF, Terabe M, Kapoor V,ElGindi M, et al: NAFLD causes selective CD4(+) T lymphocyte loss and promotes hepatocarcinogenesis. Nature 531: 153-257, 2016.

28. Wang Z, Wang J, Xie R, Liu R and Lu Y: Mitochondria-derived reactive oxygen species play an important role in doxorubicin-induced platelet apoptosis. Int J Mol Sci 16: 11087-11100, 2015.

29. Bhat AH, Dar KB, Anees S, Zargar MA, Masood A, Sofi MA and Ganie SA: Oxidative stress, mitochondrial dysfunction and neurodegenerative diseases; a mechanistic insight. Biomed Pharmacother 74: 101-110, 2015.

30. Liu J, Zhang J, Ren L, Wei J, Zhu Y, Duan J, Jing L, Sun Z and Zhou X: Fine particulate matters induce apoptosis via the ATM/P53/CDK2 and mitochondria apoptosis pathway triggered by oxidative stress in rat and GC-2spd cell. Ecotoxicol Environ Saf 180: 280-287, 2019.

31. Hauseman ZJ, Harvey EP, Newman CE, Wales TE, Bucci JC Mintseris J, Schweppe DK, David L, Fan L, Cohen DT, et al: Homogeneous oligomers of pro-apoptotic BAX reveal structural determinants of mitochondrial membrane permeabilization. Mol Cell 79: 68-83.e7, 2020.

32. Wei Y, Yu S, Zhang Y, Zhang Y, Zhao H, Xiao Z, Yao L, Chen $S$ and Zhang J: NDRG2 promotes adriamycin sensitivity through a Bad/p53 complex at the mitochondria in breast cancer. Oncotarget 8: 29038-29047, 2017. 